I will only add that I feel assured that although you may have been previously acquainted with the facts I have stated, you will, nevertheless, excuse my having addressed you on the present occasion.

I am, Sir, Very respectfully, Henry KNight.

To Edw. Johnstone, Esq., M.D.

Birmingham, Feb. 21, 1843.

\section{TREATMENT OF ACUTE MANIA.}

TO THE EDITORS OF THE PROVINCIAL MEDICAL JOURNAL.

Gentremen, - In common with your readers at large, I feel deeply indebted to $\mathrm{Mr}$. George Miller, in whom I fancy I recognise an old fellow student at Winchester, for the highly interesting case which he read before the Chichester Medical Society, and which he has so elegantly and ably reported in your Journal of the 4 th instant. The case appears to have been one of acute mania, with the phenomenon of catalepsy superadded, and in this light the writer has evidently viewed and treated it, although he has designated it by the term of catalepsy ulone.

Having had of late the opportunity of observing much of mania in its various forms and degrees, and having had also the practical management of some cases very similar to that most important and affecting one related by Mr. Miller, I feel in some measure justified in venturing to offer one or two suggestions on the case, chiefly with reference to the treatment to be pursued in the like melancholy instances of cerebral disease, both "so formidable and pitiable," as $\mathrm{Mr}$. M. justly characterises them.

It may not again fall to the lot of Mr. Miller to witness a scene so sad. Mania in this truly acute form does not often come under the notice of the practitioner in medicine. This case, however, strongly supports an opinion which I entertain myself, but by no means peculiar to myself, for $I$ heard it verified in the summer of last year by Dr. Davy, one of the assistant physicians of the Hanwell County Asylum, that veritable acute mania is frequently, nay, if the exciting cause be taken into consideration, almost generally a disease attended by low typhoid symptoms - in other words, by an asthenic state of the vital powers rapidly succeeded by collapse. The case in question fully illustrates this; a strictly conscientious clergyman works himself up into a condition of highly nervous irritation and excitement, " deprived of sleep at night as well as considerably emaciated for want of proper nutriment;" he then becomes maniacal, in a state of corporeal exhaustion; this irritation passes on to vascular congestion of the brain, and even to menin. geal inflammation. The early history of the case warrants this conclusion as to the then pathogno. monic state, and the appearances within the cranium revealed on dissection, are those of the two latter serious affections. It were almost superfluous to say that both these conditions are often concurrent with, and produced by, an exhausted, or anæmial, state of the body; and, from the whole of the symptoms so well described by Mr. Miller, I submit that this was the true pathology of the present case.
I do not pretend to criticise or find fault with the treatment adopted by Mr. M. and the able physician whom he met in consultation; the entire medical management was most judicious and scientific. Nor do I assume that recovery could have taken place under any circumstances; but my experience authorises me in recommending the earlier administration of nourishment and support, if not of stimulants. As early as on the 2lst of August I should have given some. thing more than "tea, coffee, or arrow root;" the latter I should have combined with wine, and this too, very possibly, even if he would have taken animal food in the solid or fluid form; or I should have allowed porter or mild malt liquor in any other shape that he might have preferred. The bitter beer, as it is called, I have known to be greatly enjoyed and to prove an excellent tonic at such time. On the 25 th and 26th, when he asked for wine, I question whether it would have been improper. The pulse on these days did not prohibit the trial.

Had the patient's system been thus supported, he could have borne rather more extensive topical de. pletion than was actually practised. From four to six ounces of blood abstracted by cupping-glasses, on the $26 \mathrm{th}$, applied to the occiput or behind the ears might, perhaps, have proved servicable in relieving the con. gestion then plainly established.

It is to be regretted that mercury, known to be the most powerful remedy we have in subduing conges. tions of the blood, particularly in the encephalon, and when approximating to phlogosis or effusion, did not produce its specific influence. The difficulties in getting the remedy down by the mouth were, doubtlessly, very great, but friction with linim. or ung. hydrargyri, on various parts of the body, would have been practicable. The blistered surfaces, moreover, might have been dressed with pure calomel.

In the history of the case I cannot find when calo. mel "in small and repeated doses" was commenced; but I conclude that Mr. Miller has committed an error of the pen, in writing "calomel and opium to affect the mouth," as having entered into the treatment. I remain, Gentlemen, Your obedient servant, G. BURY.

Loughton, Essex, March 7, 1843.

\section{MALFORMATION OF FOETUS.}

\section{TO THE EDITORS OF THE PROVINCIAL MEDICAL JOURNAL.}

Gentlemen,-If you think the following curious case of congenital deformity worthy of insertion in your valuable Journal, it is quite at your service.

$$
\text { I remain, Gentlemen, }
$$

Yours sincerely, JoHn Milthorp.

Topcliffe, near Thirsk, Yorkshire.

Mrs. P. was taken in labor of her first child on the 23rd of September, 1842. The breast presented. To my great surprise, after one leg was brought down, no other could be found, although I examined very carefully. The fætus, which was a seven months' one, lived about an hour (when born), and presented 